\title{
Darwin's naturalization conundrum disentangled: the role of phylogenetic relatedness depends on the invasion stages
}

\author{
Ali Omer ( $\square$ Ali.omer@uni-konstanz.de ) \\ University of Konstanz https://orcid.org/0000-0001-5687-3386 \\ Trevor Fristoe \\ University of Konstanz \\ Qiang Yang \\ University of Konstanz https://orcid.org/0000-0003-4210-9007 \\ Mialy Razanajatovo \\ University of Konstanz \\ Patrick Weigelt \\ University of Göttingen https://orcid.org/0000-0002-2485-3708 \\ Holger Kreft \\ University of Goettingen https://orcid.org/0000-0003-4471-8236

\section{Wayne Dawson} \\ Durham University https://orcid.org/0000-0003-3402-0774
}

\section{Stefan Dullinger}

University of Vienna https://orcid.org/0000-0003-3919-0887

\section{Franz Essl}

University of Vienna

\section{Jan Pergl}

Institute of Botany, The Czech Academy of Sciences https://orcid.org/0000-0002-0045-1974

\section{Petr Pyšek}

Institute of Botany, Czech Academy of Sciences

\section{Mark van Kleunen}

Taizhou University https://orcid.org/0000-0002-2861-3701

\section{Article}

Keywords: introduction bias, invasiveness, invasion process, naturalization success, ornamental plant, phylogenetic relatedness

Posted Date: December 15th, 2021 
DOI: https://doi.org/10.21203/rs.3.rs-1114202/v1

License: (a) (i) This work is licensed under a Creative Commons Attribution 4.0 International License. Read Full License

Version of Record: A version of this preprint was published at Nature Plants on August 11th, 2022. See the published version at https://doi.org/10.1038/s41477-022-01216-9. 


\section{Abstract}

Darwin's naturalization hypothesis predicts successful invaders to be distantly related to native species, whereas his pre-adaptation hypothesis predicts the opposite. It has been suggested that depending on the invasion stage (i.e. introduction, naturalization, and invasiveness), both hypotheses, now known as Darwin's naturalization conundrum, could hold true. We tested this by analysing whether the likelihood of introduction for cultivation as well as subsequent stages of naturalization and invasion of species alien to Southern Africa are correlated with their phylogenetic distance to the native flora of this region. While species were more likely to be introduced for cultivation if they are distantly related to the native flora, the probability of subsequent naturalization was higher for species closely related to the native flora.

Furthermore, the probability of becoming invasive was higher for naturalized species distantly related to the native flora. These results were consistent across three different metrics of phylogenetic distance. Our study reveals that the relationship between phylogenetic distance to the native flora and success of an alien species depends on the invasion stage.

\section{Main}

The translocation and introduction of species to new regions where they are not native, and their successful establishment in the wild (i.e. naturalization) ${ }^{1}$ is rapidly changing the distribution of biota e.g. ref. ${ }^{2,3}$. A subset of those naturalized alien species -the invasive ones- cause serious environmental and socioeconomic problems ${ }^{4-7}$. Rates of naturalizations, and hence also of invasions, are expected to continue to increase $e^{6,8,9}$, partly boosted by other global changes (e.g. climate and land-use changes) and increasing transport of people and goods $\mathrm{s}^{8,10-13}$. Thus, understanding the drivers of biological invasions has become a major objective in ecology.

Many studies have tried to determine the features of successful plant invaders by analyzing their functional traits (e.g. seed mass, height, mode of reproduction), native origins, and introduction history across spatial and temporal scales ${ }^{14-27}$. Another line of research has been trying to explain invasion success through taxonomic comparisons of alien and native floras ${ }^{28-30}$, because evolutionary relatedness is assumed to reflect the functional similarity of species. This approach has been fostered by the increasing availability of phylogenetic information, which allowed for more accurate estimates of the evolutionary relatedness of alien species and native species $^{31-35}$.

The interest in using evolutionary relatedness as a potential driver of invasion success started with Darwin's naturalization hypothesis ${ }^{32,36,37}$. Charles Darwin ${ }^{36}$ proposed that the more distantly related an alien species is to the native community, the more likely it will successfully establish. The reasoning behind this prediction is that distantly related alien species are functionally more distinct from native species, and that it is therefore more likely that they can utilize empty ecological niches in the resident community. However, Charles Darwin ${ }^{36}$ also proposed that alien species that are closely related to native species should be more successful because their similarity to the native species would indicate that they 
are pre-adapted to the local environmental conditions - the so-called pre-adaptation hypothesis. These apparently contradictory hypotheses are now known as Darwin's naturalization conundrum ${ }^{32,38}$.

Studies that tested Darwin's naturalization conundrum have found no consistent relationships between invasion success and evolutionary distance to native species reviewed in ${ }^{32,39}$. This might reflect that the studies considered different temporal and spatial scales, e.g. at small scales Darwin's naturalization hypothesis is likely to hold, and at large scales the pre-adaptation hypothesis is likely to hold $32,39,40$. Furthermore, most studies addressed Darwin's naturalization conundrum without considering possible differences between invasion stages $28,41-45$, but see ${ }^{38,46}$. The process of biological invasions can be subdivided into subsequent stages, and species have to pass different barriers or filters to move from one stage to the next ${ }^{1,47}$. First, species must overcome biogeographic dispersal barriers via human introduction into a new region. Although Darwin's naturalization conundrum does not make any predictions regarding the introduction stage, accounting for this stage is important because the vast majority of naturalized plants have been introduced intentionally for economic uses (e.g. as ornamental plants), and these plants are not a random phylogenetic subset of the global flora ${ }^{48}$. Ignoring such introduction bias can result in the over- or underestimation of the importance of species' traits underlying naturalization success ${ }^{25}$. Once a species has been introduced, phylogenetic relatedness to the native flora may impact success in subsequent stages in different ways. It is plausible that in order to establish self-sustaining populations (i.e. to become naturalized) in a region, it is important that a species is preadapted to the new environment ${ }^{49}$, which is likely the case when there are closely related natives $28,39,50$. However, in order to reach the next stage of invasion (i.e. become dominant and widespread - being invasive), it may be beneficial to be different from the native species and capitalize on unoccupied niches, which is likely when there are no closely related natives. We hence hypothesize that distinguishing between the different stages of invasion $39,51,52$ might provide new insights into Darwin's naturalization conundrum.

The evolutionary relatedness of naturalized species to native floras has typically been compared to the relatedness expected when the naturalized species would have been randomly drawn from the global flora e.g. ref. ${ }^{29,53,54}$. Such a test relies on the unrealistic assumption that there has been no bias with regard to the phylogenetic affinity and characteristics of the introduced species and that all species have had the same opportunity to naturalize. However, the pool of introduced species from which the naturalized ones emerged is often phylogenetically biased ${ }^{48}$. Information on the pool of alien species introduced to a region for cultivation, in addition to information on naturalized and native species, would be necessary to allow accounting for biases that might be associated with the selection of species for introduction ${ }^{28,42}$. Furthermore, when assessing drivers of plant invasions, one should consider that relationships may be non-linear (i.e. hump or U-shaped) ${ }^{18}$. To improve our understanding of plant invasion-success drivers, we hence need to quantify and account for biases associated with the introduction stage ${ }^{25,55}$ and to test for non-linear effects ${ }^{40}$. 
Here, we study 5,091 alien angiosperm species that have been introduced to Southern Africa for cultivation ${ }^{56}$. Combined with lists of the global flora, the naturalized and native species within the region of Southern Africa, and the species that have become invasive within the country of South Africa (Fig. 1), we test the Darwin's naturalization conundrum at the different stages of the invasion process. Specifically, we asked how phylogenetic relatedness to native species is correlated with the subsequent stages of introduction, naturalization and invasiveness of alien species.

\section{Results}

\section{The introduction and naturalization transitions}

We found that of all the 299,833 angiosperm species that are not native to Southern Africa, $899(0.29 \%)$ have become naturalized in at least one of Southern Africa's subregions. Among the phylogenetic distance models explaining the likelihood of being naturalized, phylogenetic distance to the most closely related native species $\left(\mathrm{PD}_{\mathrm{Min}}\right.$ ) provided the best model fit (i.e. had the lowest $\mathrm{AIC}$ ), followed by weighted mean phylogenetic distance to the native species $\left(\mathrm{PD}_{\mathrm{wM}}\right.$ ean) and mean phylogenetic distance to the native species ( $\mathrm{PD}_{\text {Mean }}$ ) (Table S1). The likelihood of naturalization of a species from the global species pool decreased significantly for species more distantly related to the native flora according to all three phylogenetic indices (Fig. 3a, b, c; Table S1).

When accounting for introduction bias by considering the two transitions -to the introduction for cultivation, and from introduction to naturalization - separately, we found that of all 299,833 angiosperm species that are not native to Southern Africa, 5,091 (1.69\%) have been introduced for cultivation, of which 554 (10.88\%) have become naturalized in at least one subregion of Southern Africa. For both transitions of the phylogenetic distance indices, $\mathrm{PD}_{\text {Min }}$ again provided the best model fit (Table S1). Regardless of which distance index was chosen, the probability of a species to be introduced from the global species pool into Southern Africa increased with phylogenetic distance to the native flora (Fig. 2a; Fig. 3d, e, f; Table S1), whereas the opposite was true for the probability of subsequent naturalization (Fig. 2b; Fig. 3g, h, i; Table S1). However, the amount of explained variation by the models was relatively small (all Nagelkerke $\mathrm{R}^{2}<0.1 ;$ Table $\mathrm{S} 1$ ).

\section{The naturalization-invasiveness transition}

Among the 459 introduced cultivated species that have naturalized in the country South Africa, 261 $(56.8 \%)$ are considered invasive. In the phylogenetic distance models explaining the likelihood of being invasive in South Africa, $\mathrm{PD}_{\mathrm{Min}}$ again provided the best model fit, followed by $\mathrm{PD}_{\mathrm{wMean}}$ and $\mathrm{PD}_{\text {Mean }}(\mathrm{Table}$ S2). According to the best model, naturalized species were more likely to become invasive if the phylogenetic distance to the most closely related native species is large (Fig. 2c; Fig. 4c; Table S2). Yet, the two other models revealed marginal non-linear U-shaped patterns, indicating that not only naturalized species that were distantly related to the native flora are more likely to become invasive, but also that 
naturalized species that were closely related to the native flora are more likely to become invasive than those with intermediate relatedness (Fig. 4a, b; Table S2).

\section{Discussion}

As many studies on biological invasions lack crucial data on which species have been introduced but failed to establish, we took advantage of a comprehensive list of alien plant species that have been introduced to Southern Africa for cultivation. This list allowed us to account for introduction biases in our tests of Darwin's naturalization conundrum along the different stages of the invasion process. Our results show that alien species distantly related to native species were more likely to be introduced for cultivation. Once introduced, however, those that are more closely related to native species were more likely to naturalize. On the other hand, among the naturalized species in the country of South Africa, the ones most distantly related to the natives were more likely to become invasive. Our results thus show that phylogenetic distance to the native flora has opposing effects on the transitions during the invasion process.

Humans have introduced thousands of plant species from their native regions into foreign lands. Although some of those introductions were accidental, most of them were intentional for cultivation purposes ${ }^{40,57-60}$. Moreover, it is likely that the species that have been introduced are not a random selection from the global flora but possess certain characteristics that make them of interest for cultivation ${ }^{25,55}$. This is also reflected in their phylogenetic distance to the native flora, as we found that introduction of alien species for cultivation in Southern Africa was positively associated with phylogenetic distance to the native flora (Fig. 2a; Fig. 3d, e, f; Table S1). This most likely indicates that non-native species with characteristics that are missing in the native flora were more likely to have been prospected for cultivation in Southern Africa. For example, the fact that Australian Eucalyptus species which have no close relatives in Southern Africa- grow faster and produce better wood than most native Southern African trees, made them very attractive for cultivation in forestry plantations ${ }^{61}$. The same is true for the introduction of other woody species to South Africa, that were planted for desertification control and to reduce firewood shortage ${ }^{62}$. In other words, our results are in line with the idea that humans might preferentially introduce plant species with characteristics that could provide economic and social benefits or ecosystem services that are not provided by species of the native flora.

Once introduced, not all alien species manage to grow and reproduce outside of cultivation. We found that the naturalization success of species introduced for cultivation was negatively associated with phylogenetic distance to the native flora (Figs. 2b, 3g, h, i; Table S1). In other words, and in line with the pre-adaptation hypothesis, introduced species that have closely related, and likely ecologically similar, species in the native Southern African flora were more likely to naturalize. This pattern was even visible when we considered the naturalization of all species in the global flora that are not native to Southern Africa (Fig. 3a, b, c; Table S1), despite the biased introduction of species that are distantly related to the native flora. This suggests that even if there is no information on which alien species have been 
introduced and failed to establish, comparing the naturalized ones to the global flora, as done in previous studies e.g. ${ }^{29,53,54}$, provides some indication of the importance of phylogenetic distance.

Naturalization in a new range depends on several abiotic and biotic factors ${ }^{1}$. These factors can act as filters that determine which species can in principle grow in the region, but biotic interactions such as competition can also provide resistance against the ultimate establishment of those species. It has been shown that, at least at the local scale, environmental pre-adaptation and biotic resistance are both important for alien plant naturalization $38,43,63$. However, in line with our results, at large spatial scales, environmental filtering is usually the most decisive factor for naturalization success ${ }^{28,39,50}$. One potential explanation, the pre-adaptation hypothesis proposed by Darwin ${ }^{36}$, is that introduced species closely related to the native flora share features with those native species that allow for survival and reproduction in the new range. These shared characteristics make the alien species pre-adapted to the new environmental conditions. While it is likely that closely related species have stronger competitive impacts on each other ${ }^{64-67}$ but see ${ }^{68}$, at large scales, the pre-adaptation effect may overrule the drawback of stronger competition from close relatives ${ }^{32,41,69}$. In a study that used functional traits of alien and native flora, Divíšek, et al. ${ }^{21}$ found that the similarity of alien and native species facilitates naturalization, but not invasiveness. This agreement with our study, suggests that this pattern persists even without accounting for the phylogenetic signal of species traits.

While the naturalization of introduced alien plants in Southern Africa might have occurred at sites where closely related native species happened to be present, this is less likely the case for naturalized species that have become widespread and locally dominant (i.e. invasive). In order for a naturalized species to spread and become dominant, it will have to interact with increasing numbers of native species. Those interactions are expected to be less detrimental for the alien species if it is more dissimilar to the natives, as this will allow it to avoid strong competition and common enemies by occupying vacant niches ${ }^{69,70}$. In line with this idea, we found that all naturalized species and the subset of cultivated naturalized species in South Africa were more likely to be invasive if they have no close relatives in the native flora. This has also been shown for alien trees and shrubs in Southern Africa ${ }^{71}$. It should be noted, however, that in this final stage of the invasion process, the three phylogenetic indices provided slightly different results. While the best fitting model revealed a monotonic increase of the probability of being invasive with increasing $P D_{\text {Min }}$, the other models revealed marginal non-linear U-shaped trends for $\mathrm{PD}_{\text {Mean }}$ and $\mathrm{PD}_{\text {wMean }}$. At high values of $\mathrm{PD}_{\text {Mean }}$ and $\mathrm{PD}_{\mathrm{wMean}}$, invasiveness probability also increased with increasing distance values, as it did with $P D_{M i n}$, but also showed a slight increase in probability at very low values of $\mathrm{PD}_{\text {Mean }}$ and $\mathrm{PD}_{\text {wMean }}$ (Fig. 4a, b; Table S2). This not only suggests that naturalized species are more likely to become invasive when they are phylogenetically distant from the native flora, but also that closely related species could benefit e.g. by sharing pollinators ${ }^{72}$, and that super-competitors among alien species can outcompete closely related native species ${ }^{73}$. It could also reflect that closely related species have weaker negative allelopathic effects on each other, as recently shown by Zhang, et al. ${ }^{74}$. 
Although we used three different phylogenetic distance indices, they largely revealed the same patterns. This is not surprising given that the indices are correlated. Nevertheless, models that included PD ${ }_{\text {Min }}$ had the best fit. This suggests that for successful transitions from one stage of the invasion process to the next one, the phylogenetic distance to the native species most closely related to the alien species is more important than the average distance to all native species, weighted or unweighted with regard to commonness ${ }^{32}$. In another study, however, Malecore, et al. ${ }^{43}$ found that models that used $\mathrm{PD}_{\text {Min }}$ consistently had the worst fit. This apparent discrepancy may reflect the difference in spatial scale between both studies. In our large-scale study, the most closely related native species is more likely to indicate whether there is a suitable habitat for the species somewhere in Southern Africa than the average distance to all native species does. At a smaller spatial scale, such as in the local plant communities of Malecore, et al. ${ }^{43}$, the unweighted or weighted mean distance to all native species might be a better indicator of the overall suitability of the local site for the introduced species.

In conclusion, our results show that the direction of the effect of phylogenetic distance of alien plants to the native flora alternated along invasion stages in Southern Africa. While introduction success was positively associated with phylogenetic distance to the native flora, the opposite was true for subsequent naturalization success, but invasiveness was again positively associated with phylogenetic distance. For the latter, the association might be non-linear, at least for the $\mathrm{PD}_{\text {Mean }}$ and $\mathrm{PD}_{\text {wMean }}$ indices, with a tendency that not just distantly related aliens are more invasive but also aliens that are very closely related to natives. Thus, accounting for the different invasion stages and considering multiple phylogenetic distance metrics provide more insights into Darwin's naturalization conundrum. Finally, yet importantly, the two seemingly opposing hypotheses of Darwin need not be in conflict. Rather, the mechanisms underlying them act concurrently, and the one that dominates depends on the alien species' stage along the invasion process.

\section{Methods}

\section{Study area}

Our study focuses on the region of Southern Africa, which includes 10 countries: Angola, Botswana, Eswatini, Lesotho, Malawi, Mozambique, Namibia, South Africa, Zambia and Zimbabwe, with approximately $4,000,000 \mathrm{~km}^{2}$ of land $\mathrm{area}^{71}$. As we had separate native species occurrence data for the nine provinces of South Africa, the total number of Southern African subregions was 18 (Fig. 1). Southern Africa has had a long history of plant introductions, which started in the late 18th century with the arrival of the European settlers ${ }^{75}$.

\section{The cultivated, naturalized, and invasive alien species lists}

The basis for our study is a list of over 8,000 taxa (including species and infraspecific taxa; hereafter jointly referred to as 'species') reported as being cultivated in Southern Africa in the book 'Cultivated Plants of Southern Africa' ${ }^{56}$. To allow the alignment of the list of species with other datasets used in this 
study (see below), we validated and synchronized the taxonomic names according to The Plant List (version 1.1; (http://www.theplantlist.org/) using the R package 'Taxonstand' ${ }^{\text {'6 }}$. We then removed the species that, according to The Global Inventory of Floras and Traits database (GIFT) ${ }^{77}$, are native to Southern Africa. Moreover, we removed ferns and gymnosperms as they are phylogenetically very distinct from the angiosperms. The final list of introduced species comprised 5,091 cultivated alien angiosperm species.

To identify which of the cultivated alien species have become naturalized in Southern Africa, we used the Global Naturalized Alien Flora database (GloNAF) ${ }^{78}$. GloNAF includes lists of naturalized vascular plant taxa for over 1,000 regions (usually administrative regions, such as countries, states and provinces) around the globe ${ }^{78}$. Of the 5,091 cultivated species, $554(10.8 \%)$ species have managed to naturalize in at least one sub-region following GloNAF regions ${ }^{78}$ of Southern Africa.

As invasiveness of the naturalized species might vary among the different subregions of Southern Africa, and because data on invasiveness were not available for all those subregions, we restricted the analysis of how invasiveness relates to phylogenetic distance between the alien and native species to the subset of alien species that are naturalized in the country of South Africa $(n=459)$. For this, we used the most recent list of invasive plant species of South Africa by Zengeya and Wilson ${ }^{79}$, in which invasive species are defined as widely spread species, in accordance with the unified invasion framework of Blackburn, et al. ${ }^{47}$.

\section{Global angiosperm species pool}

In order to be able to test whether the cultivated introduced plant species as well as the naturalized species are more or less phylogenetically related to the native flora of Southern Africa than expected by chance, we needed a list of the global species pool outside of Southern Africa. To get such a list, we extracted all 324,808 accepted names of angiosperm taxa from The Plant List (http://www.theplantlist.org/, last accessed in May 2019). From this list, we excluded the species that, according to GIFT, are native to Southern Africa $(n=24,974)$, resulting in a global pool of 299,834 species that are not native to Southern Africa.

\section{Phylogenetic tree of the global flora}

To compute phylogenetic distance indices between the species from the global species pool outside of Southern Africa and the native species of Southern Africa, we constructed a global phylogenetic tree of all angiosperms with accepted names according to The Plant List. In brief, as a basis for this phylogeny, we used the time-calibrated phylogeny of Smith and Brown ${ }^{80}$, which is currently the most comprehensive phylogeny for seed plants. Of the global angiosperm flora ( $n=324,808$ species), $71,133(21.9 \%)$ species were missing from the base tree. We added these missing species to their genus- or family-level root node in the base tree using the R package 'V.PhyloMaker' ${ }^{81}$. The family Haptanthaceae is missing from the base tree, and the only species belonging to this family (Haptanthus hazlettii) was excluded from our 
analysis. This resulted in a global angiosperm phylogeny of 324,807 species, of which $(n=24,974)$ are native to Southern Africa.

\section{Phylogenetic distance indices}

Several metrics can be used to describe the phylogenetic relatedness between plant species ${ }^{32}$. We selected the three most commonly used phylogenetic distance indices ${ }^{32}$. First, we calculated the mean phylogenetic distance of a focal alien species to all native species $\left(\mathrm{PD}_{\text {Mean }}\right)$. This measure assumes that the whole native flora (irrespective of the abundances of the species) contributes equally to the success or failure of the alien species. Second, we calculated the weighted mean phylogenetic distance to the native species $\left(\mathrm{PD}_{\mathrm{wMean}}\right)$. This measure weights the phylogenetic distance by the occurrence frequency of the native species, assuming that the widespread native species will be more likely to interact with the alien species. As a measure of how widespread a native species is, we used the number of Southern African sub-regions (total $n=18$; Fig. 1 ) in which it occurs according to GIFT. Third, we calculated the phylogenetic distance to the most closely related native species $\left(P D_{\text {Min }}\right)$. This measure assumes that the success of an alien species is driven by its distance to the phylogenetically nearest native species because they most likely use similar resources and share similar enemies and mutualists.

Using the global angiosperm phylogeny, we calculated for each species that is introduced for cultivation in Southern Africa its $P D_{\text {Mean }}, \mathrm{PD}_{\text {wMean }}$ and $\mathrm{PD}_{\mathrm{Min}}$ to the native flora of Southern Africa. In addition, to test for the effect of phylogenetic relatedness on the probability that a naturalized species becomes invasive in the country of South Africa, we calculated for each cultivated naturalized species in South Africa its $P D_{\text {Mean }}, P D_{\text {wMean }}$ and $P D_{\text {Min }}$ to the native flora of South Africa ( $n=15,382$, according to GIFT).

\section{Statistical analysis}

All statistical analyses were performed in $\mathrm{R}$ version 3.6.1 ${ }^{82}$. To test how introduction for cultivation, naturalization and invasiveness are associated with the phylogenetic distance indices, $\mathrm{PD}_{\text {Mean }}, \mathrm{PD}_{\mathrm{wM}}$ ean and $\mathrm{PD}_{\mathrm{Min}}$, we used a series of complementary generalized linear models (GLMs) with binomial error distribution with either a clog-log or a logit link function (see below). To see how naturalization success of the entire cultivated species relates to phylogenetic distance if one would not account for a potential introduction bias, we first tested among the entire non-native global flora how the likelihood of naturalization in Southern Africa relates to the phylogenetic distance indices. As in these analyses, the binomial response variable had many more zeros than ones, we used the clog-log link function ${ }^{83}$. Then to account for the introduction bias, we broke this analysis down into two further analyses: (1) We tested with the entire global flora not native to Southern Africa how the likelihood of being introduced to Southern Africa for cultivation relates to the phylogenetic distance indices. We again used clog-log link function in this analysis. (2) We tested among the species introduced for cultivation in Southern Africa how the likelihood of naturalization relates to the phylogenetic distance indices. As for this analysis, the numbers of zeros and ones were similar, we used the logit link function. Finally, we tested for the subset of cultivated species that have become naturalized in the country of South Africa $(n=459)$ how the 
likelihood of invasiveness relates to the phylogenetic distance indices. We also used the logit link function for this analysis. For the invasiveness analysis, we assessed the robustness of results when considering all naturalized species in South Africa according to GloNAF ( $n=799$ for South Africa), i.e. irrespective of whether they were introduced for cultivation $(n=459$ for South Africa) or not $(n=340)$. As the results of models when considering all species or the cultivated species were comparable, we present the results from the analyses using the cultivated species in the main manuscript and the results from the analyses using all species in the Appendix (Table S2).

As pairwise Pearson correlations between some of the phylogenetic indices were strong to very strong $\left(P D_{\text {Mean }}\right.$ and $P D_{\text {wMean }}: r=0.98, \mathrm{PD}_{\text {Mean }}$ and $P D_{\text {Min }}: r=0.35, \mathrm{PD}_{\text {Min }}$ and $P D_{\text {wMean }}: r=0.37$ ), we ran separate GLMs for each of them. We then used Akaike's Information Criterion (AIC) to identify which of the three phylogenetic distance indices resulted in the best model fit as $\mathrm{in}^{43}$. To test for potential non-linear humpor U-shaped relationships of introduction, naturalization and invasiveness probabilities with the phylogenetic distance indices, we also included a quadratic term for each distance index after centering the indices to means of zero. Moreover, to facilitate comparisons of the estimates within and between the models, we also scaled each explanatory variable to a standard deviation of one $e^{84}$. When the quadratic term was not significant (i.e. $P>0.05$ ), we removed it from the model. To calculate the explained deviance $\left(R^{2}\right)$ by the explanatory variables in our models, we calculated the Nagelkerke Pseudo $R^{2}$ for each GLM ${ }^{85}$ using the "rcompanion" $\mathrm{R}$ package ${ }^{86}$. To account for phylogenetic non-independence of the species, we also ran phylogenetically corrected GLMs using the 'phyloglm' function of the R package 'phylolm', ver. 2.6. $2^{87}$. However, because the results were very similar to those of the standard GLMs, we present the results of the phylogenetically corrected GLMs on in Tables S3,4.

\section{Declarations}

\section{Acknowledgements}

AO thanks the Ministry of Higher Education of Sudan and the University of Konstanz for funding, and the International Max Planck Research School for Organismal Biology for support. Mvk thanks the German Research Foundation DFG for funding (grants 264740629 and 432253815) MR thanks the DFG for funding (grant RA 3009/1-1). PP and JP were supported by EXPRO grant no. 19-28807X (Czech Science Foundation) and long-term research development project RVO 67985939 (Czech Academy of Sciences). FE appreciates funding by the Austrian Science Foundation FWF (grant I 3757-B29). We thank C. Gommel, K. Mamonova, V. Pasqualetto and B. Rüter for help with data extraction, and Lesley Henderson for providing lists of naturalized species for South Africa.

\section{References}

1. Richardson, D. M. et al. Naturalization and invasion of alien plants: concepts and definitions. Diversity and Distributions 6, 93-107, doi:10.1046/j.1472-4642.2000.00083.x (2000). 
2. van Kleunen, M. et al. Global exchange and accumulation of non-native plants. Nature 525, 100-103, doi:10.1038/nature14910 (2015).

3. Capinha, C., Essl, F., Seebens, H., Moser, D. \& Pereira, H. M. The dispersal of alien species redefines biogeography in the Anthropocene. Science 348, 1248-1251, doi:10.1126/science.aaa8913 (2015).

4. Vilà, M. \& Hulme, P. E. Non-native Species, Ecosystem Services, and Human Well-Being. In: Impact of Biological Invasions on Ecosystem Services (eds Montserrat Vilà \& Philip E. Hulme). Springer (2017).

5. Pyšek, P. et al. A global assessment of invasive plant impacts on resident species, communities and ecosystems: the interaction of impact measures, invading species' traits and environment. Global Change Biology 18, 1725-1737, doi:10.1111/j.1365-2486.2011.02636.x (2012).

6. Pyšek, P. et al. Scientists' warning on invasive alien species. Biological Reviews 95, 1511-1534, doi:https://doi.org/10.1111/brv.12627 (2020).

7. Bacher, S. et al. Socio-economic impact classification of alien taxa (SEICAT). Methods in Ecology and Evolution 9, 159-168, doi:https://doi.org/10.1111/2041-210X.12844 (2018).

8. Seebens, H. et al. No saturation in the accumulation of alien species worldwide. Nature Communications 8, 14435, doi:10.1038/ncomms14435 (2017).

9. Seebens, H. et al. Projecting the continental accumulation of alien species through to 2050. Global Change Biology 27, 970-982, doi:https://doi.org/10.1111/gcb.15333 (2021).

10. Kriticos, D. J., Sutherst, R. W., Brown, J. R., Adkins, S. W. \& Maywald, G. F. Climate change and the potential distribution of an invasive alien plant: Acacia nilotica ssp. indica in Australia. Journal of Applied Ecology 40, 111-124, doi:https://doi.org/10.1046/j.1365-2664.2003.00777.x (2003).

11. Thuiller, W., Richardson, D. M. \& Midgley, G. F. Will climate change promote alien plant invasions? In: Biological Invasions (ed Wolfgang Nentwig). Springer Berlin Heidelberg (2007).

12. Hobbs, R. J. Land-use changes and invasions. In: Invasive species in a changing world (eds Mooney HA \& Richard J Hobbs). Island Press (2000).

13. Seebens, H. et al. Global trade will accelerate plant invasions in emerging economies under climate change. Global Change Biology 21, 4128-4140, doi:https://doi.org/10.1111/gcb.13021 (2015).

14. Razanajatovo, M. et al. Plants capable of selfing are more likely to become naturalized. Nat Commun 7, 13313, doi:10.1038/ncomms13313 (2016).

15. Bucharova, A. \& van Kleunen, M. Introduction history and species characteristics partly explain naturalization success of North American woody species in Europe. J Eco/ 97, 230-238, doi:10.1111/j.1365-2745.2008.01469.x (2009).

16. Ordonez, A., Wright, I. J. \& Olff, H. Functional differences between native and alien species: a globalscale comparison. Funct Ecol 24, 1353-1361, doi:10.1111/j.1365-2435.2010.01739.x (2010).

17. van Kleunen, M., Weber, E. \& Fischer, M. A meta-analysis of trait differences between invasive and non-invasive plant species. Ecology Letters 13, 235-245 (2010).

18. van Kleunen, M., Dawson, W. \& Maurel, N. Characteristics of successful alien plants. Mol Ecol 24, 1954-1968, doi:10.1111/mec.13013 (2015). 
19. Essl, F. et al. Drivers of the relative richness of naturalized and invasive plant species on Earth. $A o B$ PLANTS 11, plz051, doi:10.1093/aobpla/plz051 (2019).

20. Winkler, D. E., Gremer, J. R., Chapin, K. J., Kao, M. \& Huxman, T. E. Rapid alignment of functional trait variation with locality across the invaded range of Sahara mustard (Brassica tournefortii). American Journal of Botany 105, 1188-1197, doi:https://doi.org/10.1002/ajb2.1126 (2018).

21. Divíšek, J. et al. Similarity of introduced plant species to native ones facilitates naturalization, but differences enhance invasion success. Nature Communications 9, 4631, doi:10.1038/s41467-01806995-4 (2018).

22. Banerjee, A. K., Prajapati, J., Bhowmick, A. R., Huang, Y. \& Mukherjee, A. Different factors influence naturalization and invasion processes - A case study of Indian alien flora provides management insights. Journal of Environmental Management 294, 113054, doi:https://doi.org/10.1016/j.jenvman.2021.113054 (2021).

23. Ni, M. et al. Invasion success and impacts depend on different characteristics in non-native plants. Diversity and Distributions 27, 1194-1207, doi:https://doi.org/10.1111/ddi.13267 (2021).

24. Fristoe, T. S. et al. Dimensions of invasiveness: Links between local abundance, geographic range size, and habitat breadth in Europe's alien and native floras. Proc Natl Acad Sci U S A 118 (22) e2021173118, doi:10.1073/pnas.2021173118 (2021).

25. Omer, A. et al. Characteristics of the naturalized flora of Southern Africa largely reflect the nonrandom introduction of alien species for cultivation. Ecography, doi:10.1111/ecog.05669 (2021).

26. Pyšek, P. et al. Naturalization of central European plants in North America: species traits, habitats, propagule pressure, residence time. Ecology 96, 762-774, doi:https://doi.org/10.1890/14-1005.1 (2015).

27. Omer, A., Kordofani, M., Gibreel, H. H., Pyšek, P. \& van Kleunen, M. The alien flora of Sudan and South Sudan: taxonomic and biogeographical composition. Biological Invasions 23, 2033-2045, doi:10.1007/s10530-021-02495-7 (2021).

28. Duncan, R. P. \& Williams, P. A. Darwin's naturalization hypothesis challenged. Nature 417, 608-609, doi:10.1038/417608a (2002).

29. Daehler, C. C. Darwin's naturalization hypothesis revisited. Am Nat 158, 324-330, doi:10.1086/321316 (2001).

30. Pyšek, P. Is there a taxonomic pattern to plant invasions? Oikos 82, 282-294, doi:10.2307/3546968 (1998).

31. Tan, J., Pu, Z., Ryberg, W. A. \& Jiang, L. Resident-invader phylogenetic relatedness, not resident phylogenetic diversity, controls community invasibility. Am Nat 186, 59-71, doi:10.1086/681584 (2015).

32. Thuiller, W. et al. Resolving Darwin's naturalization conundrum: a quest for evidence. Diversity and Distributions 16, 461-475, doi:https://doi.org/10.1111/j.1472-4642.2010.00645.x (2010).

33. Loiola, P. P. et al. Invaders among locals: Alien species decrease phylogenetic and functional diversity while increasing dissimilarity among native community members. J Ecol 106, 2230-2241, 
doi:https://doi.org/10.1111/1365-2745.12986 (2018).

34. Lososová, Z. et al. Alien plants invade more phylogenetically clustered community types and cause even stronger clustering. Global Ecol Biogeogr 24, 786-794, doi:https://doi.org/10.1111/geb.12317 (2015).

35. Marx, H. E., Giblin, D. E., Dunwiddie, P. W. \& Tank, D. C. Deconstructing Darwin's Naturalization Conundrum in the San Juan Islands using community phylogenetics and functional traits. Diversity and Distributions 22, 318-331, doi:https://doi.org/10.1111/ddi.12401 (2016).

36. Darwin, C. On the Origin of Species by Means of Natural Selection Or the Preservation of Favoured Races in the Struggle for Life. (John Murray, 1859).

37. Procheş, Ş., Wilson, J. R. U., Richardson, D. M. \& Rejmánek, M. Searching for phylogenetic pattern in biological invasions. Global Ecol Biogeogr 17, 5-10, doi:https://doi.org/10.1111/j.14668238.2007.00333.x (2008).

38. Diez, J. M., Sullivan, J. J., Hulme, P. E., Edwards, G. \& Duncan, R. P. Darwin's naturalization conundrum: dissecting taxonomic patterns of species invasions. Ecology Letters 11, 674-681, doi:https://doi.org/10.1111/j.1461-0248.2008.01178.x (2008).

39. Cadotte, M. W., Campbell, S. E., Li, S. P., Sodhi, D. S. \& Mandrak, N. E. Preadaptation and naturalization of nonnative species: Darwin's two fundamental insights into species invasion. Annu Rev Plant Biol 69, 661-684, doi:10.1146/annurev-arplant-042817-040339 (2018).

40. van Kleunen, M., Bossdorf, O. \& Dawson, W. The ecology and evolution of alien plants. Annual Review of Ecology, Evolution, and Systematics 49, 25-47, doi:10.1146/annurev-ecolsys-110617062654 (2018).

41. Park, D. S., Feng, X., Maitner, B. S., Ernst, K. C. \& Enquist, B. J. Darwin's naturalization conundrum can be explained by spatial scale. Proceedings of the National Academy of Sciences 117, 10904-10910, doi:10.1073/pnas.1918100117 (2020).

42. Diez, J. M. et al. Learning from failures: testing broad taxonomic hypotheses about plant naturalization. Ecol Lett 12, 1174-1183, doi:https://doi.org/10.1111/j.1461-0248.2009.01376.x (2009).

43. Malecore, E. M., Dawson, W., Kempel, A., Müller, G. \& van Kleunen, M. Nonlinear effects of phylogenetic distance on early-stage establishment of experimentally introduced plants in grassland communities. J Eco/ 107, 781-793, doi:https://doi.org/10.1111/1365-2745.13059 (2019).

44. Schaefer, H., Hardy, O. J., Silva, L., Barraclough, T. G. \& Savolainen, V. Testing Darwin's naturalization hypothesis in the Azores. Ecol Lett 14, 389-396, doi:https://doi.org/10.1111/j.14610248.2011.01600.x (2011).

45. Strauss, S. Y., Webb, C. O. \& Salamin, N. Exotic taxa less related to native species are more invasive. Proceedings of the National Academy of Sciences of the United States of America 103, 5841-5845, doi:10.1073/pnas.0508073103 (2006).

46. Li, S.-p. et al. The effects of phylogenetic relatedness on invasion success and impact: deconstructing Darwin's naturalisation conundrum. Ecol Lett 18, 1285-1292, 
doi:https://doi.org/10.1111/ele.12522 (2015).

47. Blackburn, T. M. et al. A proposed unified framework for biological invasions. Trends Ecol Evol 26, 333-339, doi:10.1016/j.tree.2011.03.023 (2011).

48. van Kleunen, M. et al. Economic use of plants is key to their naturalization success. Nat Commun 11, 3201, doi:10.1038/s41467-020-16982-3 (2020).

49. Broennimann, O. et al. Distance to native climatic niche margins explains establishment success of alien mammals. Nature Communications 12, 2353, doi:10.1038/s41467-021-22693-0 (2021).

50. Carboni, M. et al. What it takes to invade grassland ecosystems: traits, introduction history and filtering processes. Ecology Letters 19, 219-229, doi:https://doi.org/10.1111/ele.12556 (2016).

51. Milbau, A. \& Stout, J. C. Factors associated with alien plants transitioning from casual, to naturalized, to invasive. Conserv Bio/ 22, 308-317, doi:https://doi.org/10.1111/j.15231739.2007.00877.x (2008).

52. Dawson, W., Burslem, D. F. R. P. \& Hulme, P. E. Factors explaining alien plant invasion success in a tropical ecosystem differ at each stage of invasion. J Eco/97, 657-665, doi:10.1111/j.13652745.2009.01519.x (2009).

53. Rejmánek, M. Invasive plant species and invasible ecosystems. In: Invasive Species And Biodiversity Management (eds P. J. Schei \& A. Vilken). Kluwer Academic Publishers (1998).

54. Rejmánek, M. A theory of seed plant invasiveness: The first sketch. Biol Conserv 78, 171-181, doi:https://doi.org/10.1016/0006-3207(96)00026-2 (1996).

55. Maurel, N., Hanspach, J., Kuhn, I., Pysek, P. \& van Kleunen, M. Introduction bias affects relationships between the characteristics of ornamental alien plants and their naturalization success. Global Ecol Biogeogr 25, 1500-1509, doi:10.1111/geb.12520 (2016).

56. Glen, H. F. Cultivated Plants of Southern Africa: Botanical Names, Common Names, Origins, Literature. (Jacana: National Botanical Institute, 2002).

57. Reichard, S. H. \& White, P. Horticulture as a pathway of invasive plant introductions in the United States. Bioscience 51, 103-113, doi:Doi 10.1641/0006-3568(2001)051[0103:Haapoi]2.0.Co;2 (2001).

58. Faulkner, K. T., Robertson, M. P., Rouget, M. \& Wilson, J. R. U. Understanding and managing the introduction pathways of alien taxa: South Africa as a case study. Biological Invasions 18, 73-87, doi:10.1007/s10530-015-0990-4 (2016).

59. Dodd, A. J., Burgman, M. A., McCarthy, M. A. \& Ainsworth, N. The changing patterns of plant naturalization in Australia. Diversity and Distributions 21, 1038-1050, doi:10.1111/ddi.12351 (2015).

60. Lambdon, P.-W. et al. Alien flora of Europe: Species diversity, temporal trends, geographical patterns and research needs. Preslia -Praha 80, 101-149 (2008).

61. Bennett, B. M. Naturalising Australian Trees in South Africa: Climate, Exotics and Experimentation. Journal of Southern African Studies 37, 265-280, doi:10.1080/03057070.2011.579434 (2011).

62. Richardson, D. M. et al. The Biogeography of South African Terrestrial Plant Invasions. In: Biological Invasions in South Africa (eds Brian W. van Wilgen et al.). Springer International Publishing (2020). 
63. Li, S.-p. et al. Contrasting effects of phylogenetic relatedness on plant invader success in experimental grassland communities. Journal of Applied Ecology 52, 89-99, doi:https://doi.org/10.1111/1365-2664.12365 (2015).

64. Duarte, M., Verdú, M., Cavieres, L. A. \& Bustamante, R. O. Plant-plant facilitation increases with reduced phylogenetic relatedness along an elevation gradient. Oikos 130, 248-259, doi:https://doi.org/10.1111/oik.07680 (2021).

65. Verdú, M., Rey, P. J., Alcántara, J. M., Siles, G. \& Valiente-Banuet, A. Phylogenetic signatures of facilitation and competition in successional communities. J Eco/97, 1171-1180, doi:https://doi.org/10.1111/j.1365-2745.2009.01565.x (2009).

66. Valiente-Banuet, A. \& Verdu, M. Plant facilitation and phylogenetics. Annual Review of Ecology, Evolution, and Systematics 44, 347-366, doi:10.1146/annurev-ecolsys-110512-135855 (2013).

67. Anacker, B. L. \& Strauss, S. Y. Ecological similarity is related to phylogenetic distance between species in a cross-niche field transplant experiment. Ecology 97, 1807-1818 (2016).

68. Dostál, P. Plant competitive interactions and invasiveness: searching for the effects of phylogenetic relatedness and origin on competition intensity. Am Nat 177, 655-667, doi:10.1086/659060 (2011).

69. Levin, S. C., Crandall, R. M., Pokoski, T., Stein, C. \& Knight, T. M. Phylogenetic and functional distinctiveness explain alien plant population responses to competition. Proceedings of the Royal Society B: Biological Sciences 287, 20201070, doi:doi:10.1098/rspb.2020.1070 (2020).

70. Williams, E. W., Zeldin, J., Semski, W. R., Hipp, A. L. \& Larkin, D. J. Phylogenetic distance and resource availability mediate direction and strength of plant interactions in a competition experiment. Oecologia, doi:10.1007/s00442-021-05024-4 (2021).

71. Bezeng, S. B., Davies, J. T., Yessoufou, K., Maurin, O. \& Van der Bank, M. Revisiting Darwin's naturalization conundrum: explaining invasion success of non-native trees and shrubs in southern Africa. J Eco/ 103, 871-879, doi:https://doi.org/10.1111/1365-2745.12410 (2015).

72. Moeller, D. A. Facilitative interactions among plants via shared pollinators. Ecology 85, 3289-3301, doi:10.1890/03-0810 (2004).

73. Zhang, Z. \& van Kleunen, M. Common alien plants are more competitive than rare natives but not than common natives. Ecol Lett 22, 1378-1386, doi:https://doi.org/10.1111/ele.13320 (2019).

74. Zhang, Z., Liu, Y., Yuan, L., Weber, E. \& van Kleunen, M. Effect of allelopathy on plant performance: a meta-analysis. Ecol Lett 24, 348-362, doi:https://doi.org/10.1111/ele.13627 (2021).

75. Henderson, L. Comparisons of invasive plants in southern Africa originating from southern temperate, northern temperate and tropical regions. 2006 36, 22, doi:10.4102/abc.v36i2.362 (2006).

76. Taxonstand: Taxonomic Standardization of Plant Species Names v. 2.2 (2019).

77. Weigelt, P., König, C. \& Kreft, H. GIFT - A Global Inventory of Floras and Traits for macroecology and biogeography. J Biogeogr 47, 16-43, doi:https://doi.org/10.1111/jbi.13623 (2020).

78. van Kleunen, M. et al. The Global Naturalized Alien Flora (GloNAF) database. Ecology 100, e02542, doi:10.1002/ecy.2542 (2019). 
79. Zengeya, T. A. \& Wilson, J. R. The status of biological invasions and their management in South Africa in 2019. (South African National Biodiversity Institute, Kirstenbosch and DSI-NRF Centre of Excellence for Invasion Biology, 2021).

80. Smith, S. A. \& Brown, J. W. Constructing a broadly inclusive seed plant phylogeny. Am J Bot 105, 302-314, doi:10.1002/ajb2.1019 (2018).

81. Jin, Y. \& Qian, H. V.PhyloMaker: an R package that can generate very large phylogenies for vascular plants. Ecography 42, 1353-1359, doi:https://doi.org/10.1111/ecog.04434 (2019).

82. R: A Language and Environment for Statistical Computing v. 3.6.1 (R Foundation for Statistical Computing, Vienna, Austria, 2019).

83. Zuur, A. F., leno, E. N., Walker, N. J., Saveliev, A. A. \& Smith, G. M. Mixed effects models and extensions in ecology with R. Vol. 574 (Springer, 2009).

84. Schielzeth, H. Simple means to improve the interpretability of regression coefficients. Methods in Ecology and Evolution 1, 103-113, doi:https://doi.org/10.1111/j.2041-210X.2010.00012.x (2010).

85. Nagelkerke, N. J. D. A note on a general definition of the coefficient of determination. Biometrika 78, 691-692, doi:10.1093/biomet/78.3.691 (1991).

86. rcompanion: Functions to support extension education program evaluation v. 2.4 .1 (R package, 2021).

87. Tung Ho, L. s. \& Ané, C. A Linear-Time Algorithm for Gaussian and Non-Gaussian Trait Evolution Models. Systematic Biology 63, 397-408, doi:10.1093/sysbio/syu005 (2014).

\section{Figures}




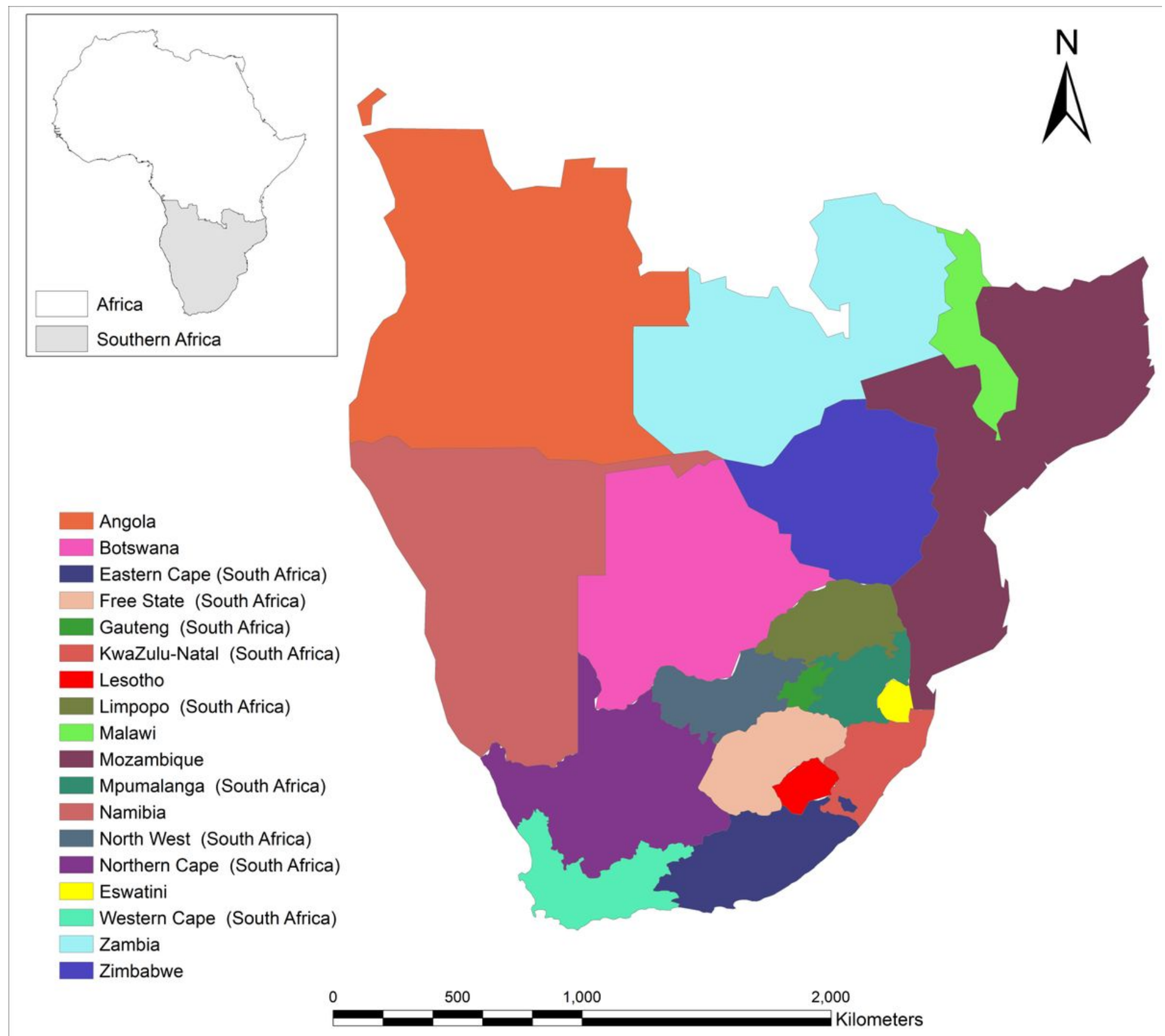

Figure 1

Map of Africa and the study regions showing the 10 countries of Southern Africa: Angola, Botswana, Eswatini, Lesotho, Malawi, Mozambique, Namibia, South Africa, Zambia and Zimbabwe. As we had separate native-species occurrence data for the nine provinces of South Africa, the total number of Southern African regions was 18. 
(a)

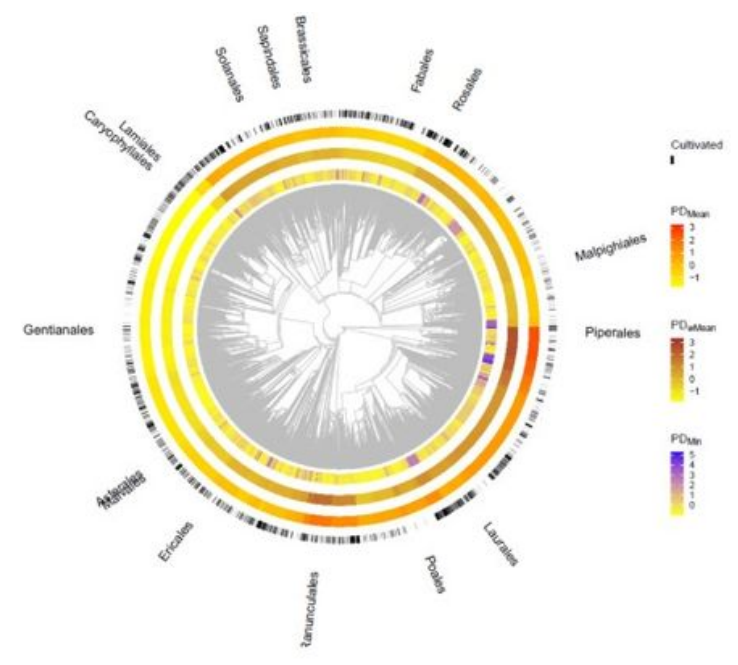

(b)

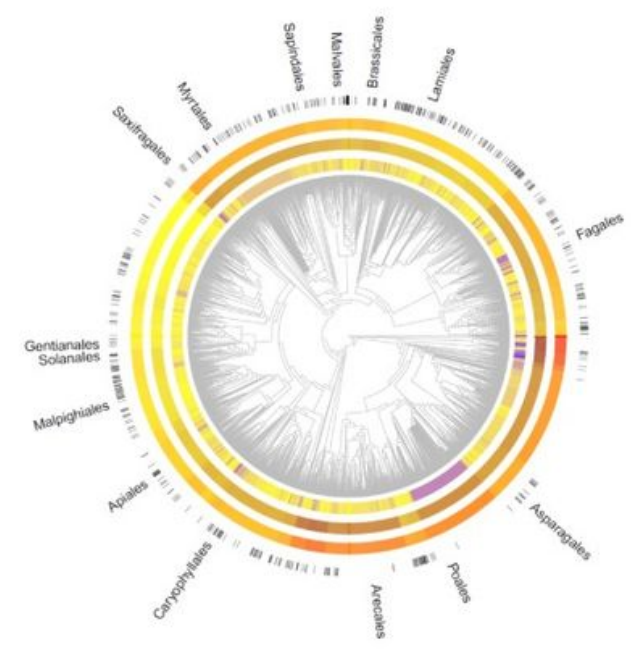

(c)

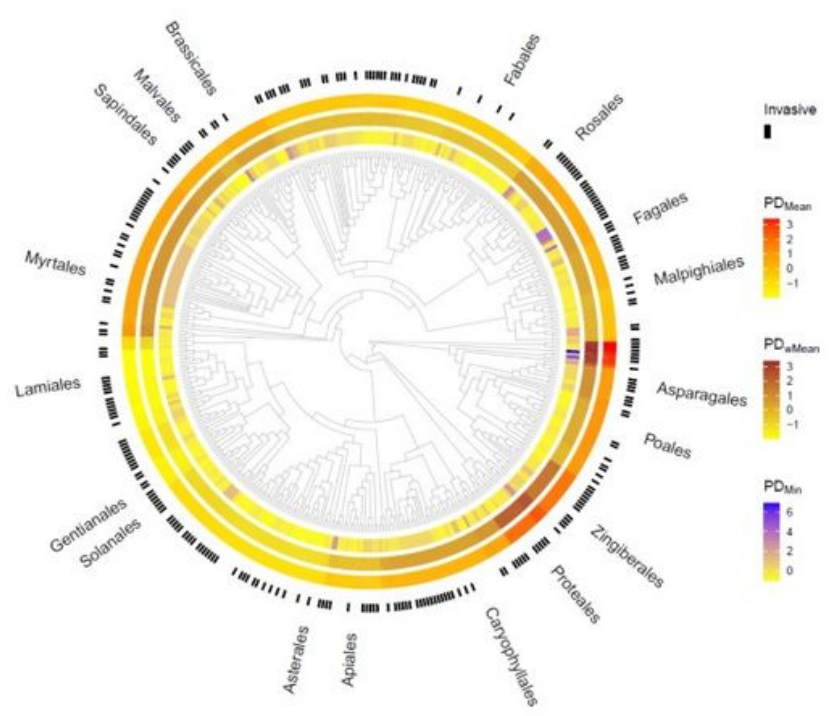

Figure 2

Phylogenetic trees showing the cultivated, naturalized and invasive species and the three indices of phylogenetic distance: (a) Phylogenetic tree of the global species pool (non-native angiosperms with accepted names in The Plant List, $n=299,833$ species). (b) Phylogenetic tree of alien species $(n=5091$ species) introduced for cultivation into Southern Africa. (c) Phylogenetic tree of naturalized species in the country of South Africa $(n=459)$. The three inner rings indicate in heat colors the three indices of phylogenetic distance to the respective native flora: mean phylogenetic distance to the native species $\left(P D_{\text {Mean }}\right)$, weighted mean phylogenetic distance to the native species $\left(P D_{\text {wMean }}\right)$, and phylogenetic distance to the nearest native species ( $\left.P D_{\mathrm{Min}}\right)$. The outer black stripes in $\mathrm{a}, \mathrm{b}$ and $\mathrm{c}$ indicate cultivated species $(n=5,091)$, naturalized species (554 species) and invasive species $(n=261)$, respectively. The names of major clades (i.e. plant orders) are provided for orientation. 

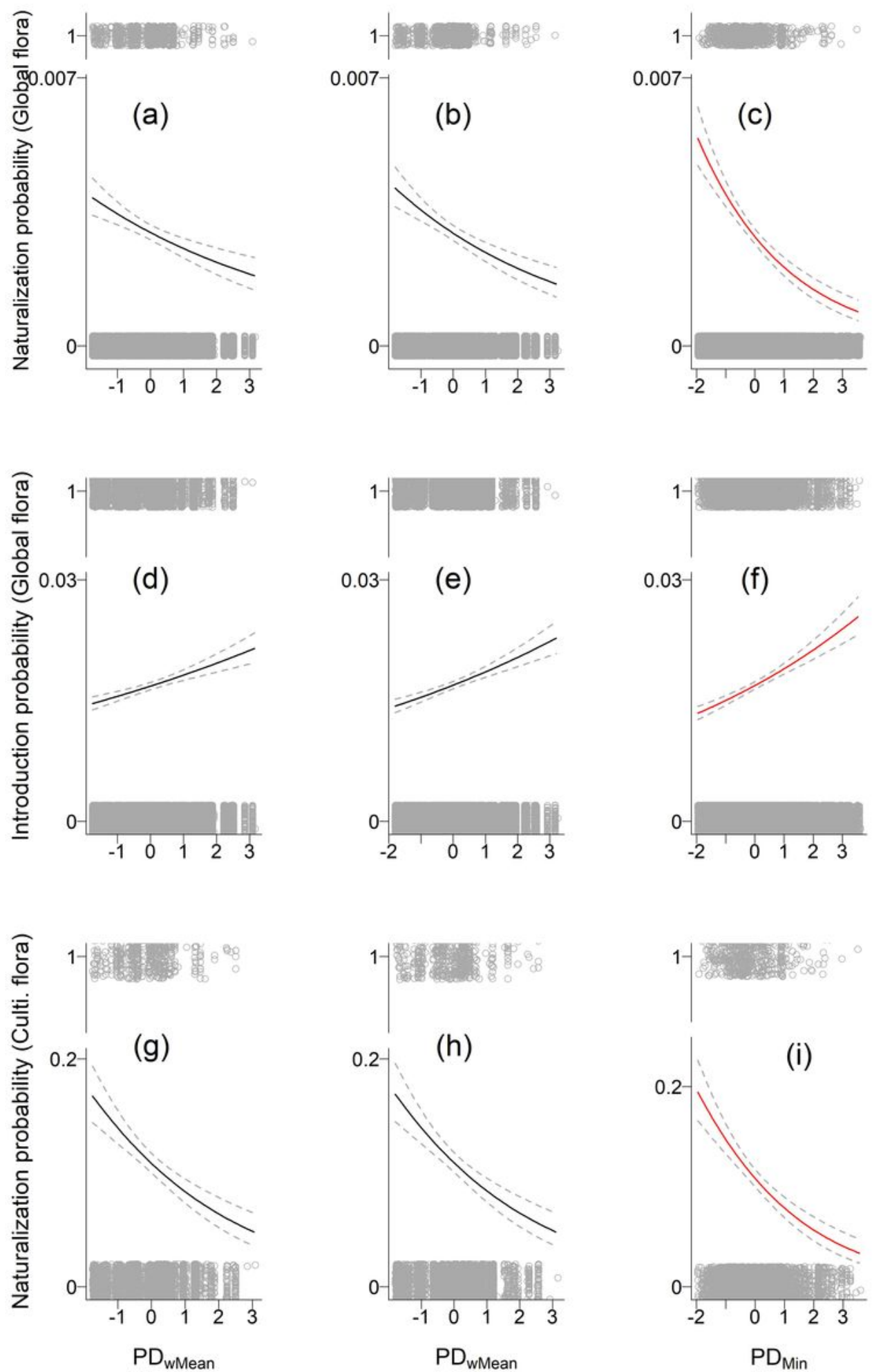

\section{Figure 3}

The probabilities of introduction and naturalization success of alien flora of Southern Africa. The probabilities of naturalization of all non-native plant species (a-c), of introduction for cultivation of all alien plant species (d-f) and of naturalization of introduced cultivated plant species in Southern Africa ( $g$ i) in relation to the different phylogenetic distance indices: mean phylogenetic distance to the native species $\left(\mathrm{PD}_{\text {Mean }} ; \mathrm{a}, \mathrm{d}, \mathrm{g}\right)$, weighted mean phylogenetic distance to the native species $\left(\mathrm{PD}_{\text {wMean }} ; \mathrm{b}, \mathrm{e}, \mathrm{h}\right)$, and 
phylogenetic distance to the nearest native species $\left(\mathrm{PD}_{\mathrm{Min}} ; \mathrm{c}, \mathrm{f}, \mathrm{i}\right)$. The solid lines are the predicted relationships from binomial GLMs (red lines indicate the best fitting model, Table1), and the dashed lines indicate the $95 \% \mathrm{Cls}$. The values of the phylogenetic distance indices of the successful and unsuccessful species are shown as open dots at one and zero, respectively (jittered to increase visibility). The values of the indices were standardized to a mean of zero and a standard deviation of one. Note the y-axis breaks.
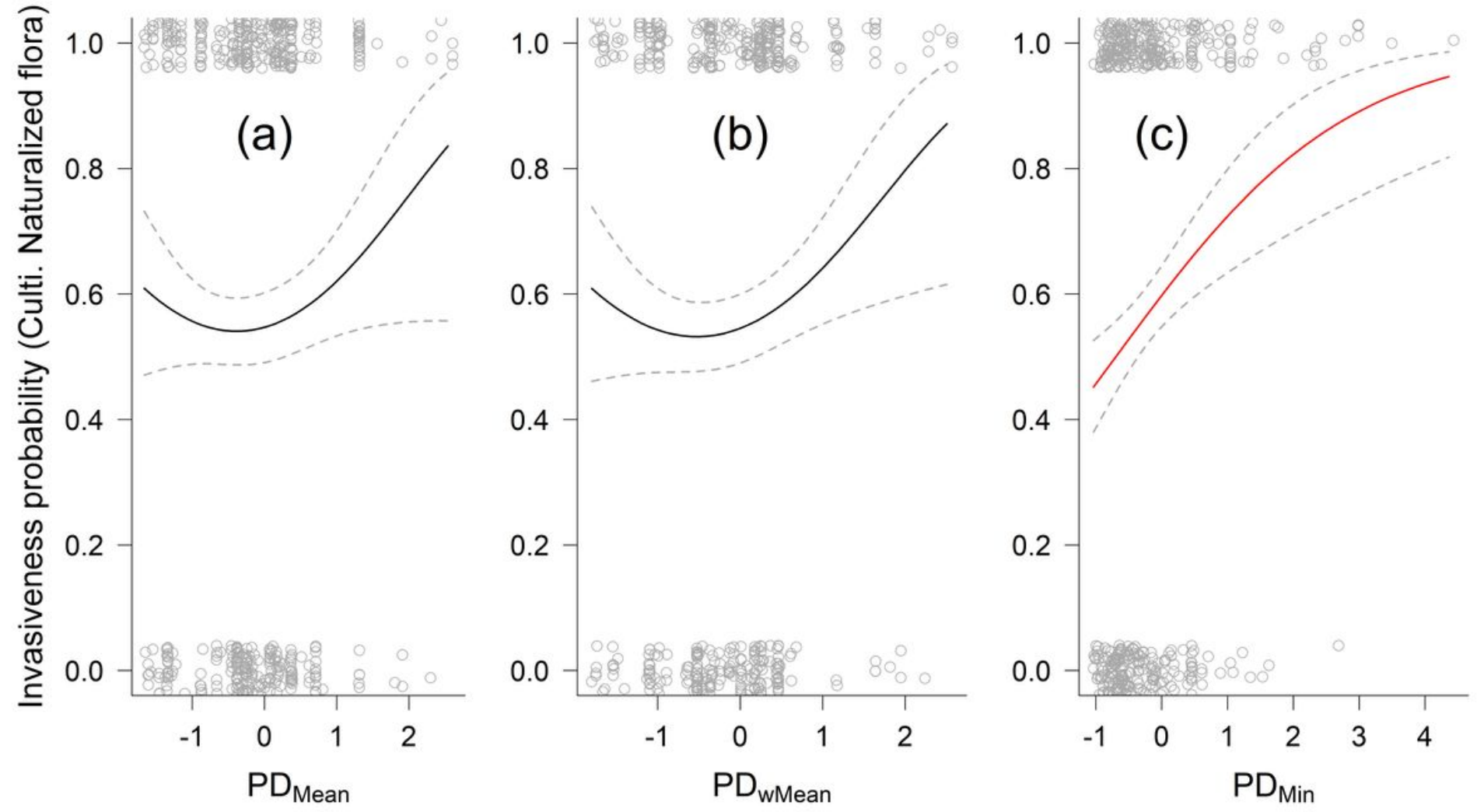

Figure 4

The probability of becoming invasive for naturalized alien plants that had been introduced for cultivation ( $n=459)$ in South Africa in relation to the different phylogenetic distance indices: mean phylogenetic distance to the native species ( $\left.\mathrm{PD}_{\text {Mean }} ; \mathrm{a}\right)$, weighted mean phylogenetic distance to the native species $\left(P D_{\text {wMean }} ; b\right)$, and phylogenetic distance to the nearest native species $\left(\mathrm{PD}_{\mathrm{Min}} ; \mathrm{c}\right)$. The solid lines are the predicted relationships from binomial GLMs (the red line indicates the best fitting model, Table 2), and the dashed lines indicate the $95 \% \mathrm{Cls}$. The values of the phylogenetic distance indices of the successful and unsuccessful species are shown as open dots at one and zero, respectively (jittered to increase visibility). The values of the indices were standardized to a mean of zero and a standard deviation of one.

\section{Supplementary Files}

This is a list of supplementary files associated with this preprint. Click to download.

- AppendixNP.docx 